\section{Commentary: Atrial fibrillation? Go hybrid}

\author{
Marco Moscarelli, MD, ${ }^{\mathrm{a}}$ and \\ Mario Gaudino, $\mathrm{MD}, \mathrm{PhD}^{\mathrm{b}}$
}

The gold standard surgical treatment for atrial fibrillation (AF) is the Cox maze procedure described in the 1980s. ${ }^{1}$ The Cox procedure is a technically complex procedure that was routinely adopted only by few dedicated surgeons. Nowadays, the majority of AF ablations are catheter-based. Because both approaches (surgical and catheter-based) have limitations and sometimes suboptimal efficacy, the hybrid and convergent technique has been proposed with encouraging results.

Varzaly and colleagues ${ }^{2}$ performed a systemic review and meta-analysis to summarize our understanding of the safety and efficacy of hybrid AF ablation. By pooling 22 studies (925 patients and 19 months of mean follow-up) they reported favorable outcomes and acceptable complication rates associated with the hybrid approach.

Surgery for AF allows direct visualization of the myocardium and a more precise and probably more complete lesions set. Also, surgery permits direct visualization of the adjacent structures (eg, the phrenic nerve) and concomitant left atrium appendage exclusion. Perhaps the biggest surgical caveat is the impossibility to map while ablating to ensure pulmonary vein isolation and block across the lesion lines. Catheter-based approaches are less invasive, may access sites unreachable from epicardium (eg, the cavotricuspid isthmus), and allow intraprocedural mapping. The hybrid approach takes the best of the 2 approaches and may achieve better AF control. Although no comparison with other approaches is made, the

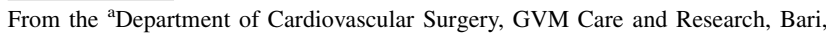
Italy; and ${ }^{\mathrm{b}}$ Department of Cardiothoracic Surgery, Weill Cornell Medicine, New York, NY.

Disclosures: The authors reported no conflicts of interest.

The Journal policy requires editors and reviewers to disclose conflicts of interest and to decline handling or reviewing manuscripts for which they may have a conflict of interest. The editors and reviewers of this article have no conflicts of interest.

Received for publication July 15, 2021; revisions received July 15, 2021; accepted for publication July 16, 2021; available ahead of print July 29, 2021.

Address for reprints: Mario Gaudino, MD, PhD, Department of Cardiothoracic Surgery, Weill Cornell Medicine, 525 E 68th St, New York, NY 10065 (E-mail: mfg9004@med.cornell.edu).

JTCVS Open 2021;7:156

2666-2736

Copyright (C) 2021 The Author(s). Published by Elsevier Inc. on behalf of The American Association for Thoracic Surgery. This is an open access article under the CC BY-NC-ND license (http://creativecommons.org/licenses/by-nc-nd/4.0/). https://doi.org/10.1016/j.xjon.2021.07.015

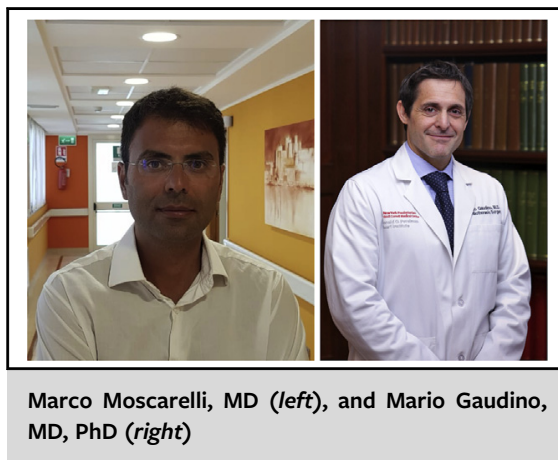

CENTRAL MESSAGE

Atrial fibrillation is a complex

disease. It needs a tailored and

multifaceted treatment and

strict collaboration between

cardiothoracic surgeons and

electrophysiologists.

results of work presented by Varzaly and colleagues ${ }^{2}$ are promising. However, some points need further discussion.

- The treatment for AF is very heterogeneous, with different ablation lines and sources of energy; hence, results may vary across studies, as demonstrated in the forest plots of Varzaly and colleagues' ${ }^{2}$ meta-analysis, with little effect size clustering and significant numerical heterogeneity.

- AF is a volatile outcome. To better evaluate the efficacy and effectiveness of the procedures (catheter based vs surgical vs combined/hybrid) we should shift the focus to clinical outcomes and patients' quality of life.

$\mathrm{AF}$ is a complex disease. As such, it needs a tailored and multifaceted treatment and strict collaboration between cardiothoracic surgeons and electrophysiologists.

\section{References}

1. Cox JL, Schuessler RB, D'Agostino HJ Jr, Stone CM, Chang BC, Cain ME, et al. The surgical treatment of atrial fibrillation. III. Development of a definitive surgical procedure. J Thorac Cardiovasc Surg. 1991;101:569-83.

2. Varzaly JA, Lau DH, Chapman D, Edwards J, Worthington M, Sanders P. Hybrid ablation for atrial fibrillation: a systematic review and meta-analysis. J Thorac Cardiovasc Surg Open. 2021;7:141-54. 